\title{
Rheology and pressure loss measurements of silt samples extracted from a dam reservoir
}

\author{
M. Belhadri ${ }^{1}$, A. Nemdili ${ }^{2} \&$ A. Ladouani ${ }^{1}$ \\ ${ }^{I}$ Department of Hydraulic, Laboratory LRTTFC, \\ Technical University of Oran, Oran, Algeria \\ ${ }^{2}$ Department of Marine Engineering, Laboratory LRTTFC, \\ Technical University of Oran, Oran, Algeria
}

\begin{abstract}
In this paper rheology and pressure loss measurements of fully developed silt flow in circular, axisymetric and horizontal conduits are presented. The silt samples studied have been taken at two different distances from the considered dam reservoir.

It was found that for small values of silt concentrations, the silt behaves like a Newtonian fluid. Above a concentration limit, its behavior is like a Bingham one; a non-Newtonian behavior. The measured pressure losses indicated that the pressure loss of silt mixture flow increase with increasing mixture concentration. The comparison of pressure loss coefficients characteristics for the three different conduits show that the pressure loss coefficient is independent of the conduit diameter.
\end{abstract}

Keywords: silt, concentration, rheology, pressure loss, conduits.

\section{Introduction}

Fluids such as silt, crude oil and its derived products occurring in transport installations have a complex flow structure and behavior. Much of their flow aspects in conduits and singularities are very little known.

Silt transported by Algerian rivers and settling in dam reservoirs has physical properties of soils of the clay type. Previous works have shown that granulometry of this silt at the deflocculated state varies between 1 and $50 \mu \mathrm{m}$ and a distinct granulometric classification exits in the basin of each reservoir. 
In the Fergoug reservoir (Algeria), the grain nominal diameter $d_{50}$ varies between 1 to $4 \mu \mathrm{m}$ near the dam and increases in the direction of the reservoir entry, reaching values of 40 to $50 \mu \mathrm{m}$, Belhadri [1], Benaddou [2].

These silts are in general flocculated due to the presence of diluted salts, which causes an increase in the real size of the particles and hence an increase in the fall velocity. Flocculation concerns mainly particles with $\mathrm{d}_{50}$ less than $40 \mu \mathrm{m}$ and size of flocculated particles in the natural state is much higher than that the elementary state and varies between 10 to $80 \mu \mathrm{m}$. The falling velocity of silt flakes varies between 0.1 and $1.0 \mathrm{~mm} / \mathrm{s}$, Belhadri [1] and Parzonka [3].

After sedimentation, the silts settle relatively quickly and reach after a few hours concentrations higher than the limit concentration of the non-Newtonian behaviour. This kind of behavior may also appear in river flows. During river flood, concentration of silted water varies between 50 and $150 \mathrm{~g} / \mathrm{l}$, which correspond to volumetric concentrations of 2 to $6 \%$. Concentration limits of clay vary between 3 and $10 \%$ whereas those of mud vary between 7 and $14 \%$.

The study of hydraulic transport in conduits of silts of high concentrations is very important, in order to decrease the energy consumption during silt pumping and should also allow the determination of the optimal transport velocity, relatively low but high enough to prevent blocking of conduits, Migniot [5].

The present experimental study consists in carrying out tests of solid-liquid transport in conduits on an installation at the Hydraulic Department of the Technical University of Oran, comprising three different conduits, in order to study a possible scale effect. The rheological properties of silt and the pressure loss of silted water in horizontal conduits are investigated.

\section{Physical, geotechnical and rheometric properties of the studied silt samples}

The studied silt samples have been taken at two different distances from the Fergoug reservoir:

- The first sample denoted 1 , have been taken upstream of the reservoir at a distance of $5,3 \mathrm{~km}$ from the dam at the side of the river called "Oued ElHammam". This sample represents the silt at the reservoir entry.

- The second sample denoted 2 have been taken near to the bottom outlet, representing the finer silt deposited downstream of the reservoir.

Observation under microscope of the silt from Fergoug reservoir shows that these sediments are composed of fine particles of irregular forms. According to previous works, specific density of solid particles of this silt varies between 2500 and $2700 \mathrm{~kg} / \mathrm{m}^{3}$. The silt under present study was found to have values of 2650 and $2700 \mathrm{~kg} / \mathrm{m}^{3}$ for samples 1 and 2 respectively, Belhadri [1].

From the granulometric curves of studied samples in the natural state (flocculated) and the elementary state (deflocculated), see Figure 1, it may be noted that granulometric curves for the deflocculated samples are regular, showing a uniform distribution of its grains. However, granulometric curves of the samples at their natural state show a flocculation of the particles with 
diameters less than about $75 \mu \mathrm{m}$. For bigger particles, the effect of flocculation disappears and both curves tend to meet on a straight line. For sample 1, the maximum grain diameter is about $500 \mu \mathrm{m}$. Its nominal diameter $\mathrm{d}_{50}$ is $80 \mu \mathrm{m}$ at the natural state and $40 \mu \mathrm{m}$ at the deflocculated state. For the sample 2, the maximum grain diameter is about $200 \mu \mathrm{m}$. Its nominal diameter $\mathrm{d}_{50}$ is $6 \mu \mathrm{m}$ at the natural state and $2 \mu \mathrm{m}$ at the deflocculated state.

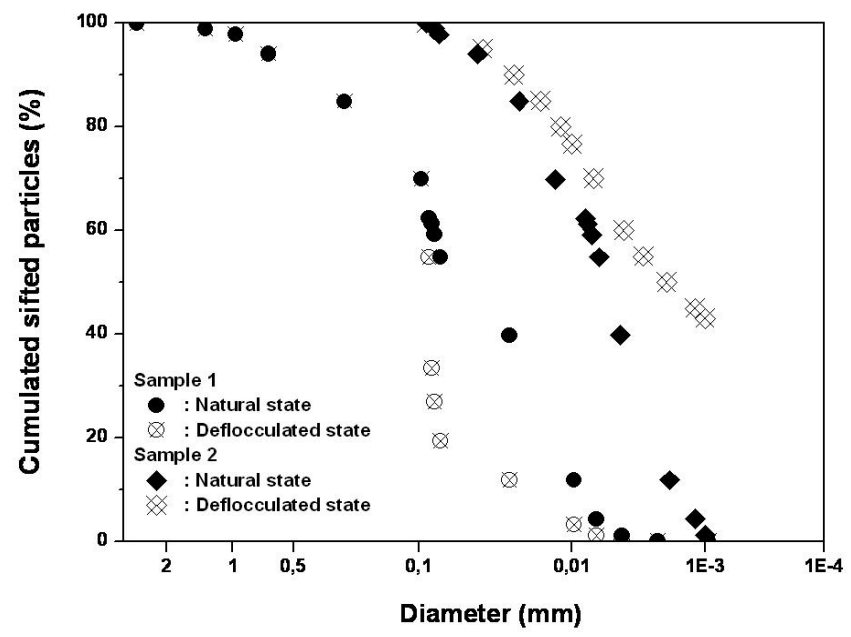

Figure 1: Granulometric curves for the studied silt samples at both natural and deflocculated states.

Physical and geotechnical properties of the studied silts are shown in the Table 1 below, Belhadri [1].

Table 1: $\quad$ Physical and geotechnical properties of the studied silts.

\begin{tabular}{|c|c|c|c|c|c|c|c|}
\hline Sample & $\begin{array}{c}\rho_{\mathrm{S}} \\
\left(\mathrm{kg} / \mathrm{m}^{3}\right)\end{array}$ & $\begin{array}{c}\mathrm{W}_{\mathrm{LL}} \\
(\%)\end{array}$ & $\begin{array}{c}\mathrm{W}_{\mathrm{LP}} \\
(\%)\end{array}$ & $\begin{array}{c}\mathrm{CV}_{\mathrm{LL}} \\
(\%)\end{array}$ & $\begin{array}{c}\mathrm{Cv}_{\mathrm{LP}} \\
(\%)\end{array}$ & $\begin{array}{c}\mathrm{d}_{50} \\
\text { natural } \\
(\mu \mathrm{m})\end{array}$ & $\begin{array}{c}\mathrm{d}_{50} \\
\text { deflocculated } \\
(\mu \mathrm{m})\end{array}$ \\
\hline 1 & 2650 & 32,6 & 22,9 & 53,7 & 62,2 & 80,0 & 40,0 \\
\hline 2 & 2670 & 61,0 & 31,2 & 38,0 & 54,6 & 6,0 & 2,0 \\
\hline
\end{tabular}

where $\rho_{\mathrm{S}}$ is the density of solid fraction,

$\mathrm{W}_{\mathrm{LL}}$ is the water content for Atterberg's liquidity limit,

$\mathrm{W}_{\mathrm{LP}}$ is the water content for plasticity limit,

$\mathrm{CV}_{\mathrm{LL}}$ is the volumetric concentration for liquidity limit,

and $\mathrm{Cv}_{\mathrm{LP}}$ is the volumetric concentration for plasticity limit.

In other work, other physical parameters, such as the sphericity factor (grain form) are used, Migniot [5]. Such factors have a secondary influence in our case, since the free fall of fine particles transported by Algerian rivers is characterized 
by the fluid viscosity, according to Stockes law, and also by flocculation and aggregation of the grains.

Rheometric characterization of homogeneous mixtures has been carried out for varying concentrations. Bingham and Newton empirical laws were used to represent flow behavior for concentrations well below the Casagrande liquidity limit. An experimental test rig was set up and used in order to measure pressure loss for different flow regimes. It is noted that for small values of silt concentrations, the silt under study behaves like a Newtonian fluid. Above this value limit, its behavior is a Bingham one. Limiting concentration values have been determined using a rotating viscometer for the non-Newtonian zone and the Engler viscometer for the Newtonian zone. Both samples under study have been characterized under simple shearing using a rotating viscometer with two coaxial cylinders of the Couette-Searle type in the non-Newtonian zone, and using an Engler viscometer in the Newtonian zone.

Figure 2 shows the characteristic of shear wall stress against shear rate deduced from pressure loss measurements in the three considered conduits with diameters $D_{1}, D_{2}$ and $D_{3}$ equal to 36,$16 ; 53,37$ and $81,13 \mathrm{~mm}$ respectively and with considered flow similar to capillary rheometry.

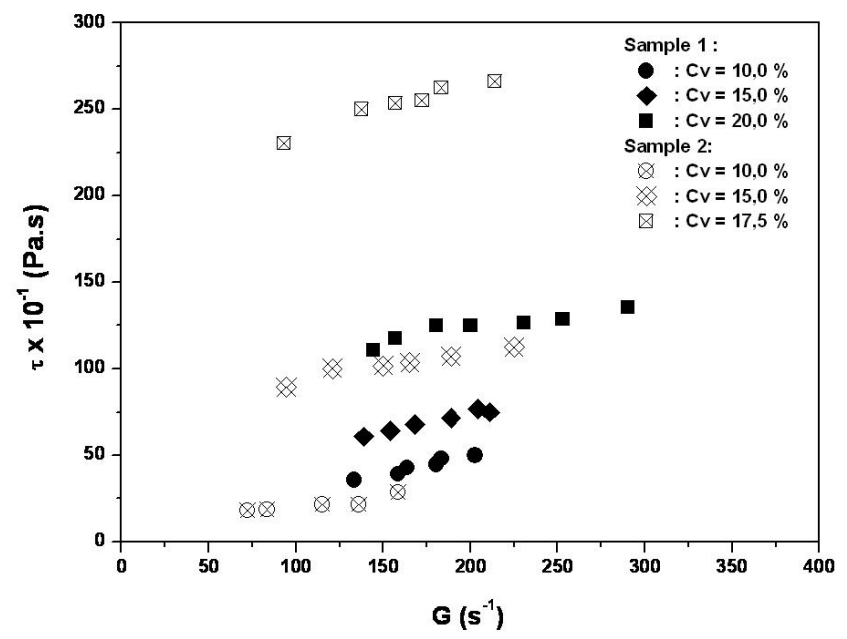

Figure 2: $\quad$ Flow curve - Shear stress against Shear rate.

The Bingham model allows the correct representation of the behavior of the studied material, for concentrations above the concentration limit $\mathrm{Cv}_{\text {limit. }}$. And for lower concentrations, the Newtonian model is adopted.

\section{Pressure loss measurements in conduits}

\subsection{Description of the test rig of charged fluid transport}

Flow parameters of the silt mixtures in conduits have been determined using the test rig shown in Figure 3. 
The installation, which is a closed circuit, comprises three loops of different diameters $\mathrm{D}_{1}=36,16 \mathrm{~mm}, \mathrm{D}_{2}=53,37 \mathrm{~mm}$ and $\mathrm{D}_{3}=81,13 \mathrm{~mm}$, with lengths equal to $12,24 \mathrm{~mm}, 18,52 \mathrm{~mm}$ and $26,30 \mathrm{~mm}$ respectively. Downstream of each measurement section, an observation window is fitted allowing a view of the settling velocity limit of the particles on the bottom of the conduit. The three conduits, made of galvanized steel, are fed by a Diesel engine driven a centrifugal pump with maximum flow rate $\mathrm{Q}$ of $20 \mathrm{l} / \mathrm{s}$ and nominal manometric head $\mathrm{H}$ of $10 \mathrm{~m}$.

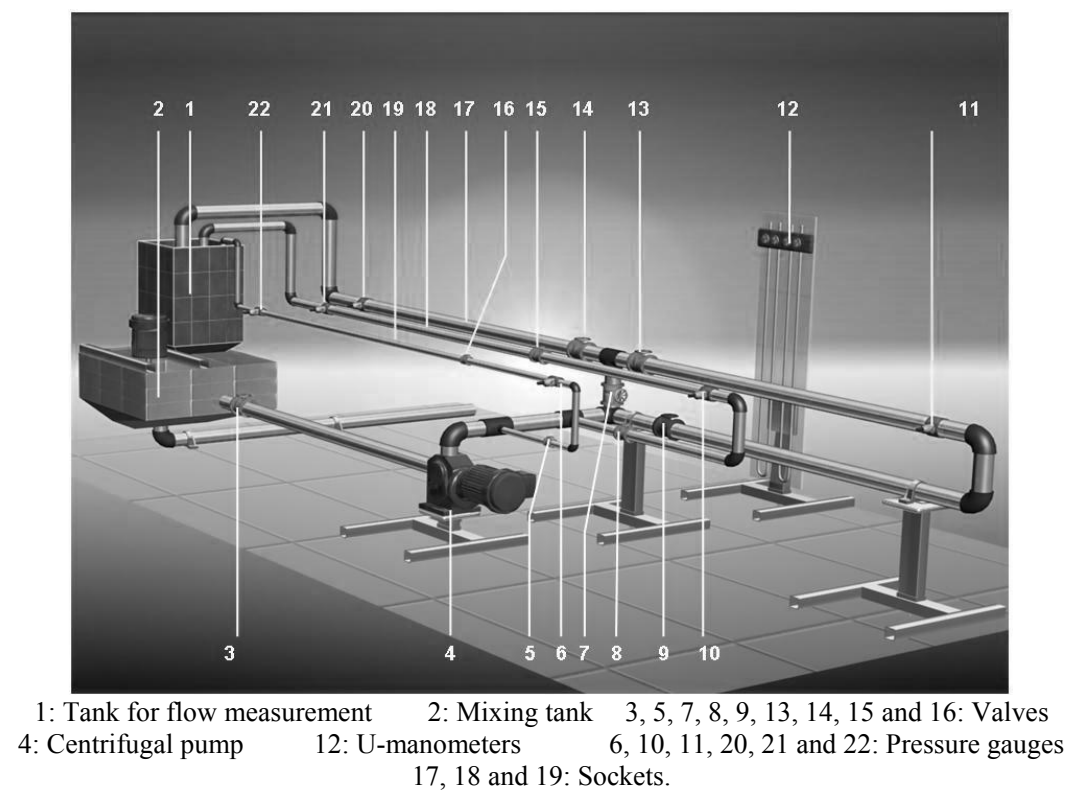

Figure 3: General layout of test stand.

The pump of a maximum manometric head of $30 \mathrm{~m}$ is connected to the tank via a one meter long galvanized tube with a diameter equal to $106,39 \mathrm{~mm}$. Internal conduit diameters are measured using an internal gauge with a precision of $0,01 \mathrm{~mm}$. The lengths of test sections were measured using a graduated rule with a precision of $5 \mathrm{~mm}$ and were found to be of 3,495;6,310 and 7,982 $\mathrm{mm}$ respectively. Upstream of each measurement section, a sufficient entry length is provided allowing a fully developed flow to establish. The length of each upstream conduit is equal to 1,$5 ; 1,62$ and $1,5 \mathrm{~m}$ respectively. The length of each downstream conduit is equal to 2,4;2,8 and 5,23 m respectively. A tank with a volume of 400 liters is provided and used for preparing mixtures at the required concentration, and feeds the three conduits through the centrifugal pump. The maximum volume of reservoir for flow measurements is about 200 , which allows a measurement time of 10 seconds for high flow rates in the turbulent regime. For lower flow rates which correspond to the laminar regime, graduated two liters glass tube is used. Pressure tapings are fitted at both ends of each 
measurement section and connected to manometers. Draining orifices of diameter equal to $6 \mathrm{~mm}$ are provided at the tapping allowing to purge the tubes between the pipes and the differential manometer and hence for reducing errors resulting from blocking of the tapings by the solid particles.

\subsection{Flow in conduits}

A flow characteristic number may be established for the flow in inertial regime using the Buckingham and Reiner equation simplified by Reiner and Filatov.

Figure 4 shows the relationship between the mixture pressure loss and the mean flow velocity for mixture concentration considered and for the smallest diameter only. Similar results were obtained for the two other considered diameters.

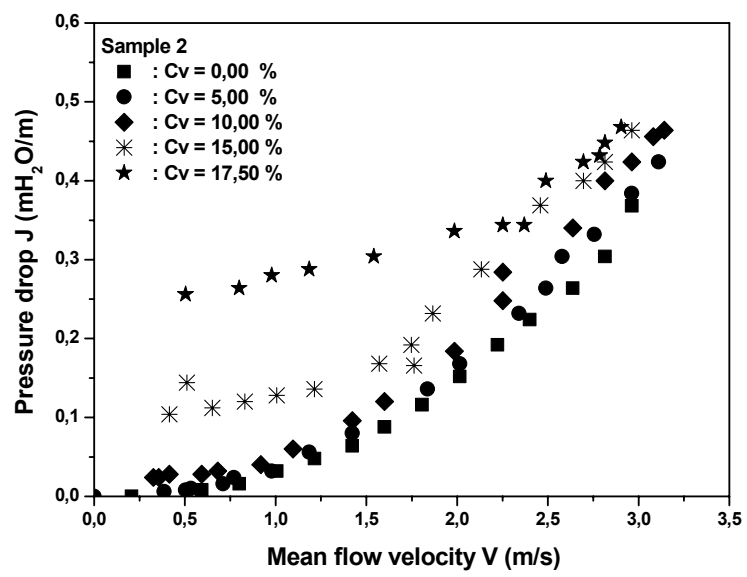

Figure 4: Relationship between pressure drop and mean flow velocity.

It may be noted that pressure loss increases with increasing velocity and is higher than that of water. It also increases with increasing $\mathrm{Cv}$. For low velocity values, the rate of pressure loss change depends on the concentration and the grain size. For $\mathrm{Cv}=5 \%$, pressure loss curves are more regular for both samples and approach that of water. For $\mathrm{Cv}=10 \%$, pressure loss curves are nearly parallel to that of water for velocities higher than the critical velocity, Vcr. For lower values of Vcr, the pressure drop of mixtures is much higher than the pressure drop of water, especially for low flow velocities slightly higher that the limit deposit velocity, $\mathrm{V}_{\mathrm{L}}$. This increase in pressure loss is more obvious for mean concentration values of $15 \%$ for both considered samples. The change in the slope of the pressure loss curves occurs at the critical flow velocity which depends on mixture concentration and size of particles, $\mathrm{d}_{50}$.

The limit deposit velocity, $\mathrm{V}_{\mathrm{L}}$, depends on concentration and particle size and is noted only for concentration values lower than $15 \%$ for sample 1 and $10 \%$ for sample 2 . Above these values, the mixture flows as a solid block. 
Figures 5 to 7 represent the loss pressure coefficient $\lambda$ according to the generalized Reynolds number $\mathrm{Re}_{\mathrm{g}}$ for the studied vases. For each diameter of the studied conduits, the variation of the pressure loss for various concentrations according to the mean flow velocity $\mathrm{V}$ is represented. The loss pressure coefficient $\lambda$ is calculated from the equation of Darcy-Weissbach. It is noted that in the case of the laminar flow, the experimental points follow with a good precision the line of Poiseuille. These results confirm the validity of the representation of $\lambda$ according to $\mathrm{Re}_{\mathrm{g}}$ for the homogeneous and quasihomogeneous flows of the mixtures of fine particles, whose viscosity is calculated using the model of Bingham. The pressure losses increase with the speed $\mathrm{V}$ and they are higher for clear water, and they grow with the increase in concentration $\mathrm{CV}$.

The obtained results are similar to those of other authors for homogeneous and quasi-homogeneous mixtures, Fam et al. [6], Parzonka and Kempinski [7] and Boczarski and Parzonka [8].

For lower speeds, the evolution of the pressure loss depends on the concentration and the particles size. For a concentration $\mathrm{Cv}$ of $5 \%$, the evolution of the curve is regular for the both vases, and the values of the pressure losses approach those of clear water. For a concentration $\mathrm{Cv}$ of $10 \%$, the curves of pressure loss evolve almost parallel to that of water for speeds higher than the critical speed Vcr. But below Vcr, the pressure drops of mixture are definitely higher than the pressure drop of water, especially for the low speeds slightly higher than the limiting speeds of deposition. This increase in the pressure loss is even clearer for the average concentrations of $15 \%$ and $20 \%$ for the vase 1 and of $15 \%$ and $17,5 \%$ for the vase 2 .

The shape of the obtained curves for the non-Newtonian vases is in conformity with the observations of other authors for concentrated homogeneous and quasi-homogeneous suspensions Tichonczuk [9].

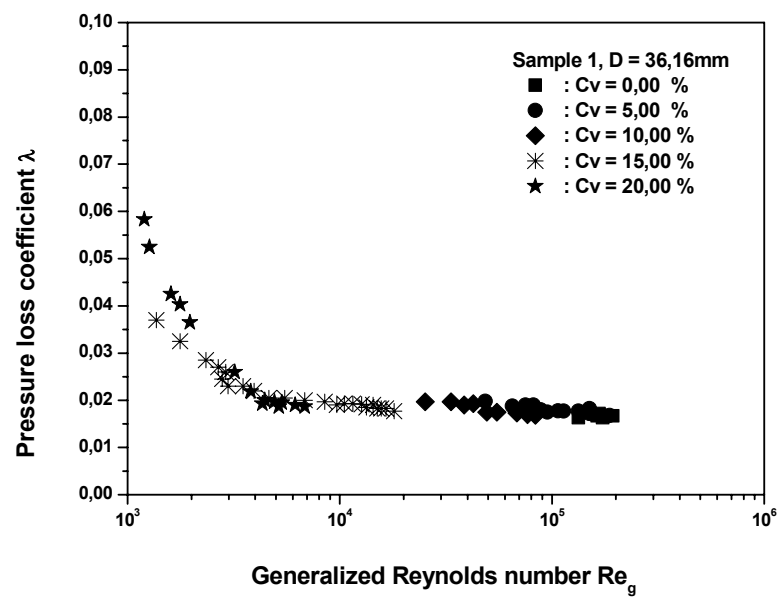

Figure 5: Pressure loss coefficient against generalized Reynolds number for sample 1 and $\mathrm{D}=36,16 \mathrm{~mm}$. 
The critical speed of passage from laminar flow to turbulent flow corresponds to the change of loss of the curve of the pressure drop of mixture versus the mean flow velocity, and depends especially on concentration $\mathrm{Cv}$ and the particles size $d_{50}$. The limit speed of deposition depends on the concentration and on the size of the particles, and is observable only for concentrations lower than $15 \%$ for the vase 1 , and $10 \%$ for the vase 2 . Beyond these values, one observes a stopper, which moves in conduct like a solid body.

In turbulent flow, the obtained results for concentrations higher than $\mathrm{Cv}_{\text {limit }}$ show that all the points of measurements are placed in the hydraulically smooth zone, lower of the Blasius curve for the pure fluid (water). It is also to note that the viscosity is a very important factor in the case of homogeneous mixtures flows; the larger viscosity is, the more the points of measurements tend to approach the laminar zone. When the viscosity is low, i.e. $\mathrm{Cv}$ little than $\mathrm{Cv}_{\text {limit }}$, the measurement points move away from the laminar zone, and are placed just at lower of the Colebrook-White curve.

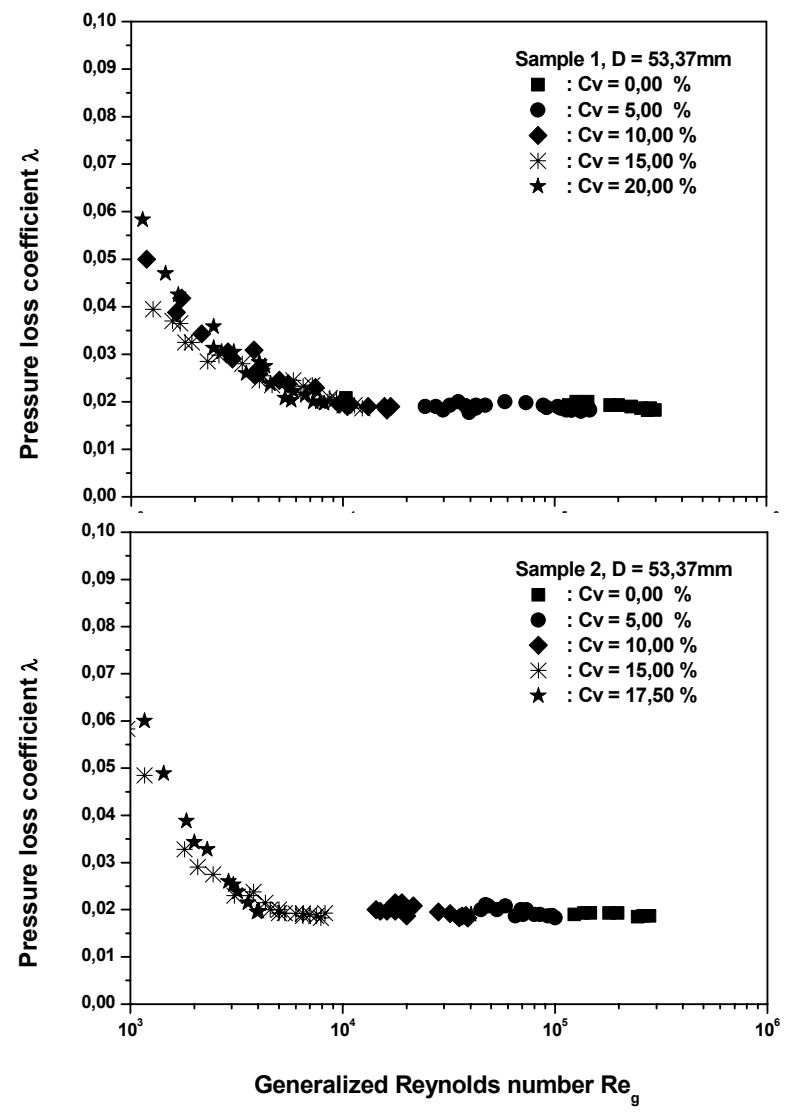

Figure 6: $\quad$ Pressure loss coefficient against generalized Reynolds number for both samples and $\mathrm{D}=53,37 \mathrm{~mm}$. 
By comparing the curves $\lambda=\mathrm{f}\left(\mathrm{Re}_{\mathrm{g}}\right)$ for the three considered conduits, we don't note a visible scale effect, regarding to the conduit diameter $D$. This makes possible the use our test results for the modeling of the flows in larger conduits, i.e. to transpose the laboratory results to the natural size installation, thus as practical application.

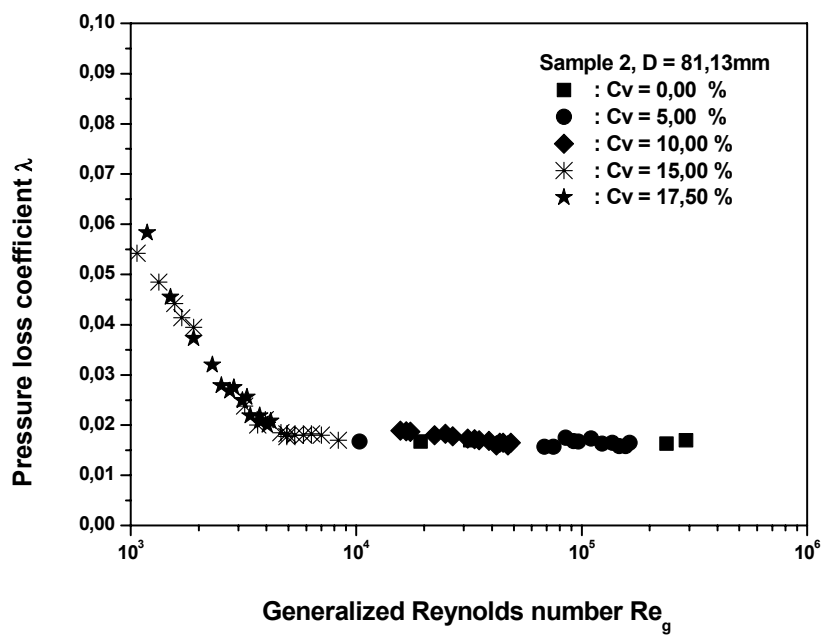

Figure 7: $\quad$ Pressure loss coefficient against generalized Reynolds number for sample 2 and $\mathrm{D}=81,13 \mathrm{~mm}$.

\section{Conclusions}

Silt in Algerian dam reservoirs has a nominal diameter $\mathrm{d}_{50}$ of particles in the elementary state between 1 and $50 \mu \mathrm{m}$. Because of presence of diluted salt in river waters, flocculation of the sediments occurs which causes an increase in granulometry and fall velocity. Flocculated particles have a nominal diameter between 10 and $80 \mu \mathrm{m}$. The studied silt samples have nominal diameters, $\mathrm{d}_{50}$ of 2 and $40 \mu \mathrm{m}$ for samples 2 and 1 respectively. For concentrations $\mathrm{Cv}$ below $\mathrm{Cv}_{\text {limit }}$, the silt mixtures behave like Newtonian Fluids and for higher values they have a non-Newtonian behaviour. Concentration limit values have been determined using a rotating viscometer for the non-Newtonian zone and a classical viscometer for the Newtonian zone. These are equal to $9,5 \%$ for sample 1 and $7,2 \%$ for sample 2. Similar values were obtained using an Engler viscometer. In the non-Newtonian zone and for mean concentration values of $15 \%$, both silt mixtures behave like Bingham Fluids. Maximum $\tau_{0}$ values observed varied between 5 and $11 \mathrm{~Pa}$.

Pressure losses were measured for both considered silt samples inside three conduits of different diameters for four different flow regimes, namely, homogeneous suspension regime, heterogeneous suspension regime, regime with a mobile flow bed and a regime with a stationary flow bed. 
The non-dimensional representation obtained using the pressure loss coefficient and the generalized Reynolds number in the Darcy-Weisbach formulae, for flow in conduits based on the Bingham model, shows that:

- The silt can be transported in conduits in the laminar regime as well as the turbulent one, and behaves like homogeneous fluids with velocities greater than homogenization velocities and behaves like quasi-homogeneous fluids with velocities less than homogenization velocities.

- The pressure loss coefficient of mixtures increases with increasing mixture concentration $\mathrm{Cv}$. It is slightly higher than that of water for turbulent flow and much higher for laminar flow. The correlation of $\lambda$ against Reynolds number $\mathrm{Re}_{\mathrm{g}}$ showed that experimental data fell on the Poiseuille line in laminar flow, and below the Blasius line for the hydraulic smooth regime.

- Comparisons of pressure loss coefficient curves for the three different conduits considered show that the pressure loss coefficient is independent of the conduit diameter.

\section{References}

[1] Belhadri M., Etude des pertes de charge pendant le transport des vases en conduites horizontales, Thèse de Magister, Institut de Génie Mécanique et Génie Civil, Université des Sciences et de la Technologie d'Oran, 1988.

[2] Benaddou B., Etude des vitesses limites de déposition pendant l'écoulement des vases en conduites horizontales, Thèse de Magister, Institut de Génie Mécanique et Génie Civil, Université des Sciences et de la Technologie d'Oran, 1987.

[3] Parzonka X., Caractéristiques rhéologiques des vases des barrages retenues, C.R. $21^{\text {ème }}$ Colloque GFR, Rhéologie des Fluides Hétérogènes, Strasbourg, 1986.

[4] A. Ladouani and A. Nemdili, Synthesis study on the silt pumping of dams, Dam Engineering, Volume XVI, Issue 1, ISSN 0-617-00563-X, May 2005, pp. 67-79.

[5] Migniot, C., Etudes des propriétés physiques de différents sédiments très fins et de leur comportement sous des actions hydrodynamiques, La Houille Blanche, 1968.

[6] D. Fam; J. A. Dodds ; D. Leclerc and O. Scrivener, Caractérisation rhéologique et écoulement en conduite de schlamns de phosphates, Entropie, 3, 1986.

[7] W. Parzonka and J. Kempinski, Etude du transport des matériaux organiques en conduites, Archiwum Hydrotechniki, Acad. Polon. Des Sciences, 1983, pp. 361-376.

[8] S. Boczarski and W. Parzonka, Estimation de l'influence de la viscosité sur les pertes de charges pendant l'écoulement des déchets de flottation de cuivre en conduites horizontales, Archiwum Hydrotechniki, Acad. Polon. Des Sciences, 1977, pp. 489-509.

[9] W. Tichonczuk, Analyse du processus de fluage des déchets de sucreries, Dissertation Dr Ingénieur, Université Technique de Varsovie, 1977. 